\title{
Recyclability, durability and water vapour adsorption of unstabilised and stabilised compressed earth bricks
}

\author{
Agostino Walter Bruno (D) Blake Scott • Yann D'Offay-Mancienne • \\ Céline Perlot
}

Received: 8 July 2020/ Accepted: 17 November 2020/Published online: 1 December 2020

(C) The Author(s) 2020

\begin{abstract}
This paper investigates the recyclability, liquid water durability and water vapour adsorption of both unstabilised and stabilised compressed earth bricks. Stabilised bricks were manufactured by adding either cement or the biopolymer guar gum to the base earth. Unconfined compressive strength tests were then performed on both unstabilised and stabilised earth bricks manufactured with recycled material (i.e. material taken from the failed compressed earth bricks after the compressive strength tests). These tests enabled to assess the influence of recycling on the stiffness, strength and strain energy of all compressed earth bricks. Immersion and drip tests were subsequently performed to investigate the effect of cement and biopolymer stabilisation on the durability of the compressed earth bricks against the weathering action of water. An additional set of laboratory experiments was finally conducted by means of a Dynamic Vapour Sorption (DVS) system to study the effect of earth stabilisation on the capacity of adsorbing/releasing
\end{abstract}

A. W. Bruno $(\varangle) \cdot$ B. Scott · Y. D'Offay-Mancienne School of Engineering, Geotechnics and Structures, Newcastle University, Devonshire Terrace Drummond Building Room 2.19, Newcastle upon Tyne NE1 7RU, UK

e-mail: agostino.bruno@newcastle.ac.uk

C. Perlot

Laboratoire SIAME, Fédération IPRA, EA4581, Université de Pau Et Des Pays de L'Adour, 64600 Anglet, France water vapour as the ambient humidity changes. Outcomes from this experimental campaign showed that both unstabilised and biopolymer stabilised earth bricks maintained a similar mechanical performance after recycling, while cement stabilised bricks showed a remarkable reduction of both stiffness and strength. Finally, both cement and biopolymer stabilised bricks improved the liquid water durability while reducing the water vapour adsorption compared with the unstabilised earth bricks. Results from this experimental work will be useful for life cycle assessments, especially for modelling the end-of-life of the material as well as its potential reuse.

Keywords Compressed earth bricks - Stabilisation · Recyclability · Mechanical properties - Liquid water durability $\cdot$ Water vapour adsorption

\section{Introduction}

The adoption of the earth in mainstream construction is recently gaining the interest of engineers, architects and material scientists because of its eco-friendly credentials. Earth can be locally sourced and this significantly reduces the overall transportation needs [1]. The manufacturing of earth materials also requires little embodied energy compared with other building materials, such as cement or fired earth [2]. During their service life, earth materials exhibit an excellent 
capacity of regulating indoor hygrothermal conditions by smoothening daily and seasonal oscillations of both relative humidity and temperature [3-10]. At the end of their service life, earth materials can be recycled or safely disposed without significant impact on the environment unlike other materials (such as concrete blocks and fired earth bricks), whose disposal generates pollution and loss of land [11]. Often, earth materials are chemically stabilised with lime or cement to improve both mechanical and water durability performance [12-17]. However, stabilisation is deemed to reduce both the hygrothermal regulator capacity and the full recyclability compared with the unstabilised earth, thus limiting its environmental performance over the entire life cycle [5, 8]. These considerations on the complete recyclability of unstabilised earth materials and the detrimental effect of stabilisation are generally based on assumptions, whereas a systematic experimental investigation on this subject is missing from the literature. Only a handful of studies have focused on the effect of recyclability on the main geotechnical properties of the earth, such as grain size distribution, plasticity and linear shrinkage [18]. The main objective of these studies was to demonstrate that the recycled earth materials still have suitable geotechnical properties for earth construction in agreement with existing recommendations. However, these studies did not show whether the resulting mechanical performance of the recycled earth matches that of the original material and whether the recycling process has induced any deterioration of the material.

To overcome this gap in the literature, this paper investigates the effect of recyclability on the mechanical behaviour of both unstabilised and stabilised compressed earth bricks. A set of bricks was stabilised by adding to the soil the biopolymer guar gum, which is a neutrally charged polysaccharide extracted from the endosperm of beans belonging to the family of Leguminosae plants [19-21]. This biopolymer was selected as it can be easily sourced and improves both stiffness and strength of earth materials while reducing permeability [22-24]. For ease of comparison, another set of bricks was instead stabilised by adding ordinary Portland cement to the soil mix. All compressed earth bricks were also subjected to various laboratory experiments (i.e. immersion tests, drip tests and dynamic vapour sorption tests) to assess the influence of soil stabilisation on the liquid water durability and water vapour adsorption. Importantly, outcomes from the present work can inspire new research into the post-service life of earth materials, which will be fundamental for life cycle assessments moving from a "cradle-to-grave" to a "cradle-to-cradle" approach and in a circular economy perspective.

\section{Material and methods}

The earth used in the present work was provided by the brickwork factory Nagen from the region of Toulouse in the south-west of France. Figure 1 shows the grain size distribution of the Nagen earth material together with the boundaries that delimit the recommended regions according to the manufacturing guidelines for compressed earth bricks provided by MOPT [25], CRATerre-EAG and AFNOR [26, 27]. The grain size distribution was determined by means of wet sieving and sedimentation as prescribed by the norms XP P94041 [28] and NF P94-057 [29], respectively. Inspection of Fig. 1 indicates that the grain size distribution of the tested material (i.e. black continuous line with filled markers) is close to the left boundary of the recommended regions (i.e. continuous grey line for MOPT [25] and dashed grey line for both CRATerreEAG and AFNOR [26, 27]), which corresponds to finer soils. As observed by Jaquin et al. [30] and Beckett and Augarde [31], finer soils can retain more water than coarser ones when exposed to the same hygrothermal conditions, thus resulting in stronger hygroscopic behaviour but potentially with a weaker water durability performance.

The plasticity properties of the fine fraction (i.e. the fraction passing through the $400 \mu \mathrm{m}$ sieve) were determined in agreement with the norm NF P94-051 [32]. The liquid limit is $33.0 \%$ while the plasticity index is $12.9 \%$, which correspond to an inorganic clay of medium plasticity according to the Unified Soil Classification System [33]. These properties satisfy the existing recommendations for the manufacture of compressed earth bricks [26, 27, 34]. The activity of the fine fraction (i.e. the ratio between plasticity index and clay fraction) is equal to 0.79 , which corresponds to a normally active soil [35]. This is also consistent with the mineralogical composition observed by Bruno et al. [36] via X-Ray diffraction tests, which indicated a predominant illitic clayey fraction with a presence of montmorillonite for the same Nagen soil. 


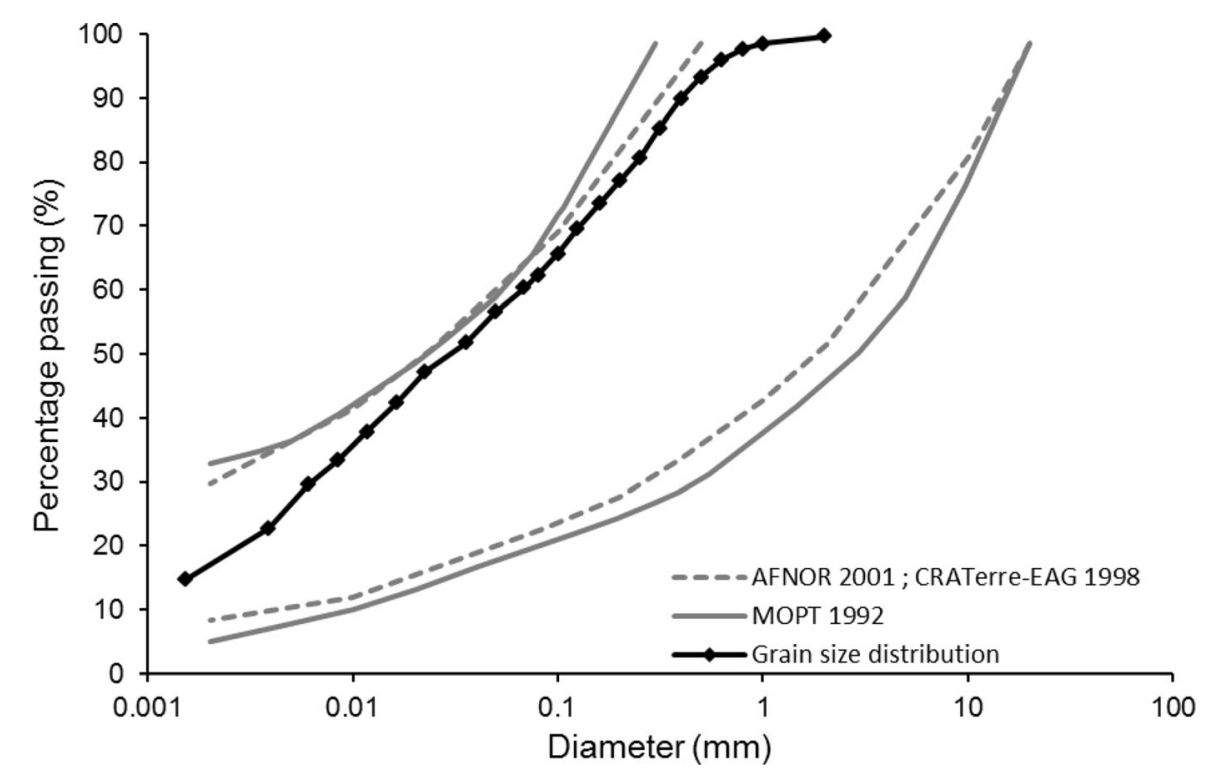

Fig. 1 Grain size distribution of tested earth

Illite is a three-layers clay with good bonding characteristics and limited swelling upon wetting, which makes it suitable for raw earth construction [37].

Before compaction, the Nagen soil was firstly dried at $105{ }^{\circ} \mathrm{C}$ for at least $24 \mathrm{~h}$ and then either a) left unamended for the unstabilised bricks or b) mixed with a guar gum content of $2 \%$ and $4 \%$ by mass of the dry soil for the biopolymer-stabilised bricks or c) mixed with a cement content of $4 \%$ and $8 \%$ by mass of the dry soil for the cement-stabilised bricks. In particular, for the biopolymer stabilised bricks, the guar gum was procured from the company $\mathrm{M} / \mathrm{s}$ Intralabs and the highest content of $4 \%$ used in the present work is slightly higher than that tested by other studies [21, 38, 39]. On the other hand, ordinary Portland cement was used for cement stabilised bricks and the highest content of $8 \%$ is such that the environmental benefits associated to the use of earth materials are severely compromised, as also observed by Bui et al. [40]. Note that, before mixing, both guar gum and cement were not dried but only stored in sealed containers at room conditions (i.e. $\mathrm{T} \cong 20^{\circ} \mathrm{C}$ and $\mathrm{RH} \cong 45 \%$ ) to avoid that the preliminary drying would affect the bonding properties of both stabilisers. This was deemed acceptable as the water content of both guar gum and cement was only negligible. The unamended soil for unstabilised bricks and soil and stabilisers for stabilised bricks were then mixed with $8 \%$ of water by means of a planetary mixer for a minimum time of $5 \mathrm{~min}$ at a relatively slow rotation rate to minimise dust generation and hence the material loss. The water content of $8 \%$ was selected based on results from [41, 42], who determined various compaction curves corresponding to different compaction energy on the same Nagen soil. The selected water content corresponded to the optimum value at a dry density of $2000 \mathrm{~kg} / \mathrm{m}^{3}$, which is the target dry density at which all bricks are compacted in the present study. Note that, for consistency, the same water content was used for both unstabilised and stabilised compressed earth bricks even though this was the optimum value only for the unstabilised material. This choice was considered acceptable as all soil mixes (i.e. both unstabilised and stabilised) exhibited good workability with the chosen level of water content. After mixing, the moist material was statically compacted in a mould with a horizontal cross-section of $200 \times 100 \mathrm{~mm}^{2}$, as shown in Fig. 2 . During compaction, an upper aluminium piston with a horizontal cross-section of $199.8 \times 99.8 \mathrm{~mm}^{2}$ was lowered inside the compacting mould until the bricks attained the desired height of $50 \mathrm{~mm}$, which corresponded to the target dry density of $2000 \mathrm{~kg} / \mathrm{m}^{3}$. Note that soil, cement and guar gum have specific gravities of $2.66,3.11$ and 1.25 , respectively. This implies that different compressed earth bricks were compacted at the same dry density but at different initial porosities, as summarised in Table 1. Inspection of Table 1 


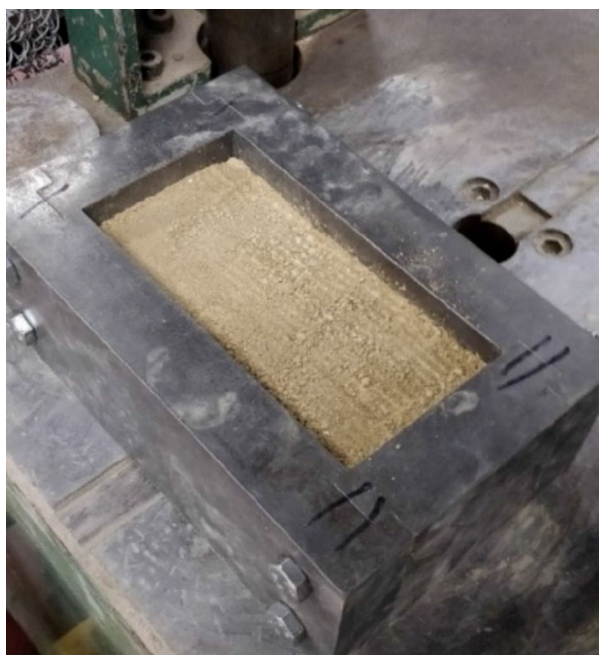

Fig. 2 Compaction mould used for manufacturing both unstabilised and stabilised compressed earth bricks

indicates that unstabilised bricks have an intermediate porosity compared with the more porous cement stabilised bricks and the less porous biopolymer stabilised bricks.

After compaction, all bricks were left to equalise at laboratory room conditions (i.e. $\mathrm{T} \cong 20{ }^{\circ} \mathrm{C}$ and $\mathrm{RH} \cong 45 \%$ ) for a minimum time of ten days until sample mass varied less than $0.1 \%$ over a period of $48 \mathrm{~h}$. At the end of this equalisation stage, all earth bricks exhibited a water content of about $3 \%$. Note that cement-stabilised earth bricks would require different curing conditions with a higher relative humidity (i.e. normally above 90\%). Instead, the drier curing conditions imposed during equalisation may have generated a non-optimised hydration of concrete and material shrinkage with a consequent formation of microcracks and tensile stresses [43]. This affected the mechanical and durability performance of cementstabilised compressed earth bricks, as it will be shown in the following sections. On the other hand, a very high relative humidity was deemed inappropriate for equalising unstabilised and guar gum-stabilised earth bricks and hence room conditions were adopted for all samples for the sake of consistency and also to reproduce real in-situ applications. After equalisation, laboratory tests were conducted to investigate the influence of recycling on the mechanical properties of both unstabilised and stabilised compressed earth bricks as well as the effect of stabilisation on liquid water durability and water vapour adsorption. The testing procedures followed during this experimental campaign are briefly summarised in the following section.

\subsection{Effect of recyclability on mechanical properties of unstabilised and stabilised bricks}

The first set of experimental tests was performed to investigate the influence of recycling on the compressive strength, stiffness and strain energy of both unstabilised and stabilised compressed earth bricks. For this purpose, after a minimum equalisation time of ten days, all bricks were subjected to unconfined compressive strength tests by means of the Instron $5585 \mathrm{H}$ press, as shown in Fig. 3. During testing, the load was applied at a controlled displacement rate of $0.5 \mathrm{~mm} / \mathrm{min}$ along the longest dimension of the bricks. All samples were therefore tested at an aspect ratio of 4 (i.e. ratio between the vertical height of the brick and the minimum dimension of the horizontal crosssection), which minimised the spurious effect of end-friction confinement generated at the contact surfaces between bricks and press plates [44, 45]. Moreover, during the compressive strength tests, each brick was placed inside an aluminium tray to ensure the collection of all the material for the subsequent recycling (Fig. 3).

Table 1 Composition and physical properties of all compressed earth bricks after compaction

\begin{tabular}{lllllll}
\hline Sample & Mass soil $(\mathrm{g})$ & Mass cement $(\mathrm{g})$ & Mass guar gum $(\mathrm{g})$ & Mass water $(\mathrm{g})$ & Dry density $\left(\mathrm{kg} / \mathrm{m}^{3}\right)$ & Porosity $(-)$ \\
\hline Unstabilised & 2000 & - & - & 160 & 2000 & 0.248 \\
$4 \%$ Cement & 1920 & 80 & - & 160 & 2000 & 0.253 \\
$8 \%$ Cement & 1840 & 160 & - & 160 & 2000 & 0.258 \\
$2 \%$ Guar gum & 1960 & - & 40 & 160 & 2000 & 0.240 \\
$4 \%$ Guar gum & 1920 & - & 80 & 160 & 2000 & 0.232 \\
\hline
\end{tabular}




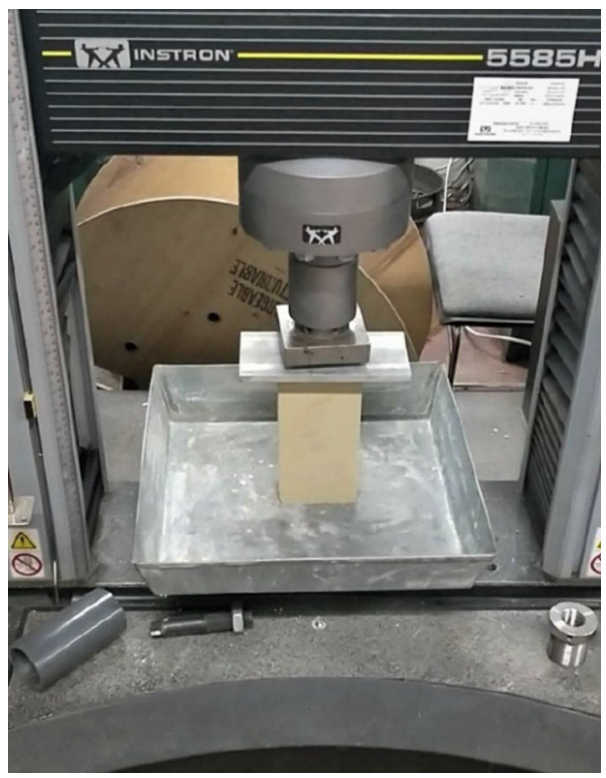

Fig. 3 Set-up for unconfined compressive strength tests

After testing and before recycling, the failed samples were collected and then dried at a temperature of $105{ }^{\circ} \mathrm{C}$ for a minimum time of $24 \mathrm{~h}$. This drying stage was considered necessary to add the correct water content during the subsequent manufacture of all the recycled compressed earth bricks. It is assumed that the drying process had only a marginal effect on the cement stabilised samples preliminarly equalised at relatively dry conditions. This is in fact due to the occurrence of two counteracting mechanisms: (a) expansion of existing microcracks and formation of new ones, which weakened the material and (b) increase of stabilising capillary actions [46]. On the other hand, the drying process induced a partial depolymerisation of the guar gum (i.e. conversion from polymers to a mixture of monomers) with a consequent reduction of the molecular weight, as observed by Bradley et al., [47] and Srivastava et al. [48]. The newly formed monomers with lower molecular weight exhibit better film forming properties and an increased bonding capacity [49]. This improved bonding of the guar gum affected the mechanical behaviour of the recycled bricks stabilised with the biopolymer, as it will be shown in the following section. After drying, the material collected from the compressive strength tests was then broken down using a plastic hammer with special care to minimise the generation of dust and material loss. The material was crushed until only the
$0.4 \%$ of the initial mass was retained by the $2 \mathrm{~mm}$ sieve, which is similar to the grain size distribution of the original material. Note that, apart for the largest particle size, the whole grain size distribution of the recycled material was not compared with that of the original one and hence the breakage of soil grains that may have been produced by the crushing was not detected. This type of study was considered outside the main scope of the present work but it constitutes matter for future research. After crushing, the dry crushed material was then mixed at a water content of $8 \%$ and then recompacted inside the mould to have a second set of compressed earth bricks. Similar to the first set of bricks, the second set of samples was also left to equalise for ten days and then tested under unconfined compressive strength tests. Note that the equalisation time was fixed to ten days in order to replicate the same conditions adopted for the first set of samples. Finally, this recycling process was again repeated to perform the third cycle of compressive strength tests. Note that the three recycling iterations will be named hereafter as Cycle I, II and III. During each recycling iteration, about 2 to $5 \mathrm{~g}$ of materials were lost in the re-manufacturing of each brick and this mass was replaced with unrecycled material with the same composition as the original brick. It is assumed that this replacement of unrecycled material had only a negligible effect on the mechanical behaviour of the recycled bricks. Furthermore, no additional stabiliser was added to the composition of the recycled cement- and guar gum-stabilised earth bricks. This was considered necessary to isolate the effect of the recycling process on the mechanical behaviour of the recycled bricks and to avoid any interferences from additional stabilisations.

The unconfined compressive strength tests enabled the measurement of the compressive strength, stiffness and strain energy of all the compressed earth bricks. In particular, the compressive strength was simply obtained as the ratio between the highest load measured during testing and the initial horizontal cross-section of the brick. The stiffness of the samples was instead determined by assuming a linear elastic behaviour for compressive stresses up to $20 \%$ of the peak strength. Finally, the strain energy, stored by each sample during unconfined compressive loading, was determined as the area under the stress-strain curve up to the peak compressive strength. 


\subsection{Liquid water durability}

The liquid water durability of all compressed earth bricks was measured by means of immersion and drip tests. The immersion tests were conducted according to the German norm DIN 18945 and provided a first assessment of the resistance of the bricks against the weathering action of water. After manufacturing and subsequent equalisation, both unstabilised and stabilised compressed earth bricks were weighted by means of a scale with a resolution of $0.01 \mathrm{~g}$ and then submerged in water for $10 \mathrm{~min}$. After immersion, all bricks were left to equalise at the same ambient conditions before immersion (i.e. $\mathrm{T} \cong 20^{\circ} \mathrm{C}$ and $\mathrm{RH} \cong 45 \%)$ until a constant mass was reached and then reweighted to determine the mass loss after immersion. Note that the water content of all bricks was approximately $3 \%$ for all bricks after the equalisation stages conducted before and after the immersion tests. The immersion test was performed on a single brick for each composition without any additional replicates. This was considered necessary to optimise the use of the available material for the other tests of the present experimental campaign. Despite this lack of repeatability, results from immersion tests are however deemed reliable as they well match the outcomes from drip tests, as it will be shown in the following sections.

The drip tests were performed according to the norm UNE 41410 [50] to assess the durability performance of both unstabilised and stabilised compressed earth bricks against rainfall-induced erosion. During the drip test, the compressed earth brick was placed on an inclined support with an inclination of $27^{\circ}$ to the horizontal and $1 \mathrm{~m}$ below a reservoir filled with 0.51 of water. The reservoir was then opened to have a controlled water flow of $0.05 \mathrm{l} / \mathrm{min}$. All bricks were therefore exposed for a duration of $10 \mathrm{~min}$ to the damaging action of water drops, that impacted at the centre of the largest face of the bricks and then rolled down due to the inclination of the sample. After testing, the depth of erosion generated by the water drops was measured by means of a calliper with a resolution of $0.01 \mathrm{~mm}$. The drip tests were performed on two bricks for each composition and this was considered acceptable as the outcomes from these two replicates were almost identical. The effect of recycling on the water durability of both unstabilised and stabilised earth bricks was not investigated and this is due to the fact that durability tests have damaged or completely destroyed the earth samples so that it was not possible to collect and recycle the material.

\subsection{Water vapour adsorption}

The effect of soil stabilisation on the water vapour adsorption of the different compressed earth bricks was investigated via dynamic vapour sorption tests, carried out by means of the DVS device from Surface Measurement Systems. These tests were performed on small fragments (about $0.25 \mathrm{~g}$ ) taken from failed compressed earth bricks from Cycle I of the unconfined compressive strength tests. Note that the compressive strength tests may have densified the earth samples but this is assumed to only have negligible effect on the DVS tests as the sorption and desorption of water vapour at a temperature of $25{ }^{\circ} \mathrm{C}$ only take place within nanometric intra-aggregate pores which are not affected by the mechanical compaction [51, 52]. During DVS testing, the small fragments were placed on a plate connected to a balance with a resolution of $0.1 \mu \mathrm{g}$ and inside a closed chamber under controlled hygrothermal conditions. Each sample was firstly equalised under dry conditions (i.e. at a relative humidity of $0 \%$ ) and at a constant temperature of $25{ }^{\circ} \mathrm{C}$ until the constant mass condition was reached. After equalisation, the relative humidity was increased in stages of $10 \%$ up to $90 \%$ plus a final stage at $98 \%$, which is the maximum humidity that can be applied by the DVS system. Following the same stages of the adsorption branch, the relative humidity was subsequently decreased back to $0 \%$, at a constant temperature of $25{ }^{\circ} \mathrm{C}$. The sample mass was continuously recorded during the cyclic variation of relative humidity and each stage lasted until the sample mass varied by less than $0.01 \%$ over a minimum time of $1 \mathrm{~h}$. The DVS test was performed on two different samples for each brick composition and again this was considered acceptable given the good repeatability of the results. Finally, the effect of recycling on the moisture buffering behaviour of both unstabilised and stabilised earth bricks was not investigated and future wok will surely focus on this subject.

Outcomes from the recyclability, liquid water durability and dynamic vapour sorption tests are presented in the following section. 


\section{Results}

\subsection{Effect of recyclability on mechanical} properties of unstabilised and stabilised bricks

The effect of earth stabilisation and recyclability was investigated by means of compressive strength tests performed on three samples for each brick composition. Figure 4 shows the average peak compressive strength and corresponding standard deviation of all compressed earth bricks over three recycling stages (i.e. Cycle I, II and III). Inspection of Fig. 4 indicates that, for the original material (i.e. Cycle I), compressed earth bricks stabilised with $4 \%$ and $8 \%$ of cement exhibited the highest compressive strength compared with unstabilised bricks and bricks stabilised with $2 \%$ and $4 \%$ of guar gum. This is due to the strong bonding of soil particles generated by cement in comparison with the more flexible polymeric chains formed by guar gum or the capillary action in unstabilised samples. After recycling, unstabilised earth bricks showed an almost identical compressive strength, thus suggesting that this material can be recycled multiple times without any loss of mechanical performance. This is because the mechanical behaviour of unstabilised samples depends on the capillary pressure $[53,54]$, which in turn is dependent on temperature, relative humidity and pore size distribution inside the material. Although the recycling process could have affected the fabric of the unstabilised material, this effect resulted to be minimal as shown by the very similar mechanical response exhibited by the unstabilised bricks over the different recycling iterations (Fig. 4). Compressed earth bricks stabilised with guar gum exhibited instead a slight increase in compressive strength and this can be due to the guar gum passing from a rubbery to a glassy state over the time of testing, as also observed by Muguda et al. [39], who observed a slight increase in the compressive strength of guar gum-stabilised samples passing from 7 to 28 curing days (i.e. upon prolonged curing). This passage from the rubbery to glassy state therefore seems not to be deteriorated by the recycling process. Moreover, the increase of the compressive strength of the biopolymer stabilised bricks can also be in part attributed to the drying stage experienced during the recycling process, which has enhanced the bonding capacity of the guar gum. Figure 4 finally shows that cement stabilised compressed earth bricks exhibited the most significant loss of compressive strength, which becomes similar to that of unstabilised earth bricks after three recycling stages, regardless of the initial cementation level. This reduction of compressive strength is attributable to the breakage of cementing bonds occurring during recycling.

Figure 5 shows the average stiffness of all compressed earth bricks together with the corresponding standard deviation. Similar to the peak compressive strength, the Young modulus of the unstabilised samples was also relatively unaffected by the

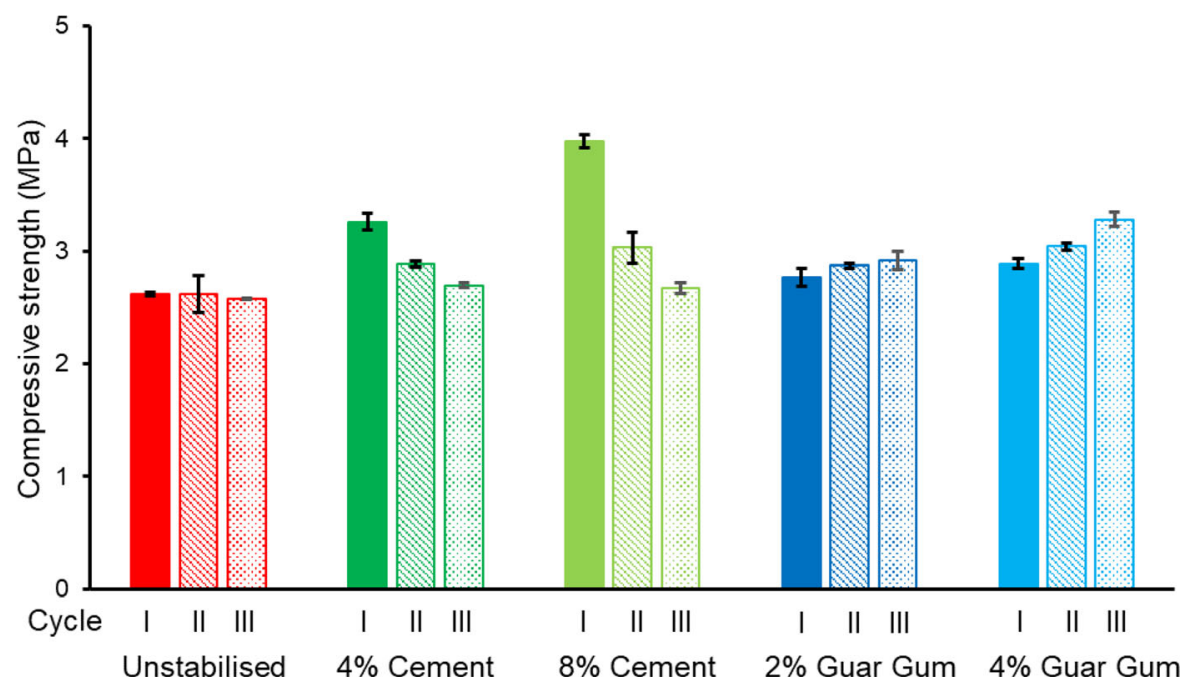

Fig. 4 Compressive strength of unstabilised and stabilised compressed earth bricks over three recycling stages (i.e. Cycle I, II, III) 
recycling process. Instead, compressed earth bricks stabilised with $4 \%$ and $8 \%$ of cement exhibited a significant reduction in stiffness during recycling, with values of Young modulus in Cycle III similar to those of the unstabilised bricks. Interestingly, the stiffness of the guar gum increased during recycling and this is due to the passage from a rubbery to a glassy state for the biopolymer as well as the improved bonding due to the drying stage of the recycling process. Inspection of both Figs. 4 and 5 suggests therefore that cement stabilisation produces stronger and stiffer bonds of the soil particles compared with the biopolymer stabilisation. However, cement bonds exhibited a more brittle behaviour upon breakage and only a negligible reactivation during mixing and subsequent re-compaction. Instead, the guar gum produced more ductile polymeric bonding chains that can be reactivated during multiple stages of recycling. Interestingly, this different effect of the recycling process on the mechanical behaviour of cement and biopolymer stabilised compressed earth bricks suggests that earth stabilisation is not necessarily detrimental to the recyclability of earth materials and bespoke investigations should be carried for each type of stabilisation.

Figure 6 shows the strain energy stored by the compressed earth bricks during unconfined compressive loading. Similar to the stiffness and strength, the strain energy of the unstabilised bricks is also only limitedly affected by the recycling process. Cementstabilised bricks exhibited a remarkable loss of strain energy with values lower than those of the unstabilised samples after three recycling stages. Guar gum stabilised bricks exhibited instead a slight increase of stored strain energy over recycling. The difference between the cement and the biopolymer stabilisations can be interpreted with a different type of bonding generated between the soil particles. In fact, cement stabilisation produced strong, stiff but brittle cementing bridges with a limited deformation capacity. This reduced the amount of strain energy that can be stored by cement-stabilised compressed earth bricks. Conversely, the polymeric chains formed by the guar gum are weaker and less stiff compared with the cement bonds but with a higher tendency of deforming under compressive loading, thus leading to a better capacity of storing strain energy.

\subsection{Liquid water durability}

The liquid water durability of both unstabilised and stabilised compressed earth bricks was investigated by means of immersion and drip tests. Results from immersion tests are presented in Fig. 7 together with the benchmark values of the mass loss as given by the norm [20]. Figure 7 shows that, as expected, the unstabilised sample exhibited the weakest resistance to water erosion with a mass loss after immersion that further confirms the results obtained by Bruno et al. [51]. Conversely, both cement and biopolymer stabilisations significantly improved the resistance of the

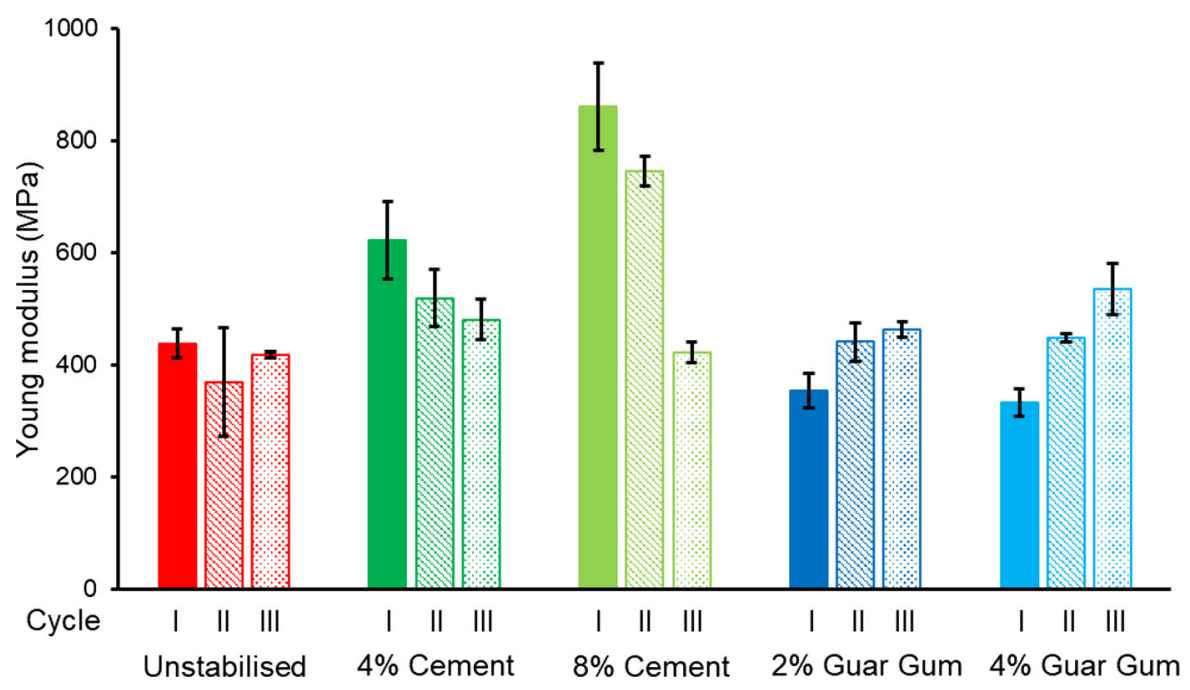

Fig. 5 Young modulus of unstabilised and stabilised compressed earth bricks over three recycling stages (i.e. Cycle I, II, III) 


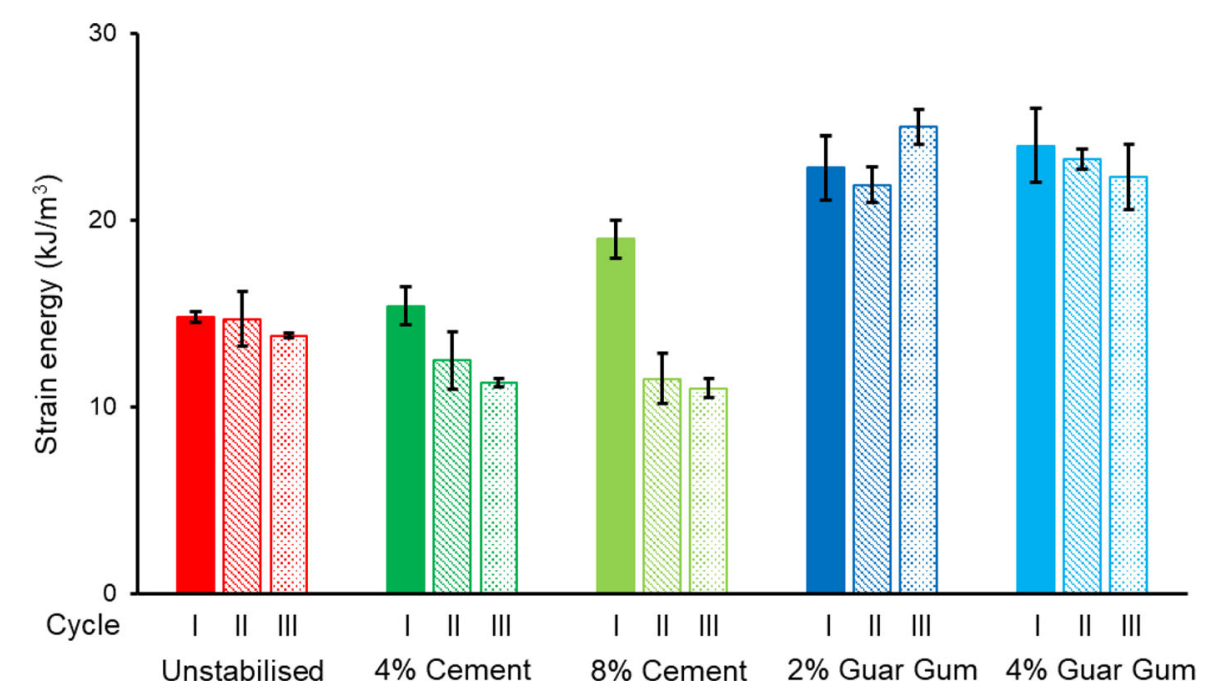

Fig. 6 Strain energy of unstabilised and stabilised compressed earth bricks over three recycling stages (i.e. Cycle I, II, III)

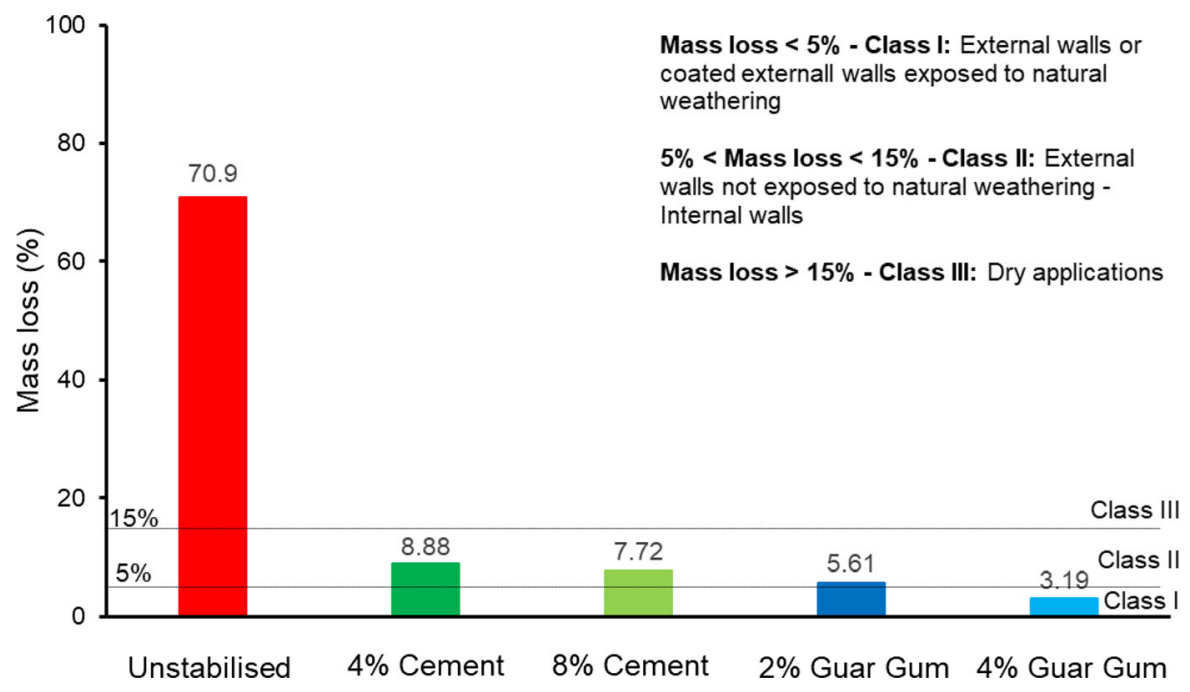

Fig. 7 Mass loss after immersion tests of unstabilised and stabilised compressed earth bricks

bricks against water erosion. Interestingly, guar gum stabilisation outperformed the cement stabilisation and this can be due to the lower porosity of the material stabilised by the biopolymer (and hence a lower permeability) as well as the more diffused stabilising effect of the polymeric chains in comparison with the localised bonds produced by the cement stabilisation. This consideration could be confirmed by microstructural testing (e.g. microscopy or porosimetry), but this type of characterisation is considered outside the scope of the present paper and it will constitute a matter for future research.
Inspection of Fig. 7 indicates that, as prescribed by the German norm DIN 18945, the unstabilised bricks could only be used for dry applications while cement stabilised bricks and bricks stabilised with $2 \%$ of guar gum could be used for internal walls or external walls not exposed to the weathering action of water (e.g. rainfall erosion, capillary rise from the foundation soil). The best performing brick stabilised with $4 \%$ of guar gum could be instead used for coated external walls exposed to natural weathering. Note that this brick classification is only indicative and other durability tests (i.e. contact test and suction test) should 
have been performed to fully categorise the application of the compressed earth bricks in agreement with the norm [20].

Figure 8 shows results from the drip tests performed on two samples for each brick composition in agreement with the norm UNE 41410 [50]. Figure 8 also shows the limiting value of erosion depth (i.e. $10 \mathrm{~mm}$ ) which provides the outcomes of the drip test in terms of pass (i.e. erosion depth lower than $10 \mathrm{~mm}$ ) or fail (i.e. erosion depth higher than $10 \mathrm{~mm}$ ). Similar to what observed from the immersion tests, also results from drip tests highlighted the weak water durability of the unstabilised bricks and the improvement induced by both cement and biopolymer stabilisation. Inspection of Fig. 8, therefore, indicates that both unstabilised and cement stabilised compressed earth bricks failed while both samples stabilised with $2 \%$ and $4 \%$ of guar gum passed the drip tests. This difference can be explained not only by the stabilising effect of the polymeric chains but also by the occlusion of the smaller pores, which limited both the swelling of the clay fraction and the subsequent cracking of the material. The assumption that the biopolymer stabilisation reduced the portion of smaller pores to a greater extent compared with the cement stabilisation is also corroborated by the results from the dynamic vapour sorption DVS tests, as it will be shown in the next section.

\subsection{Water vapour adsorption}

The capacity of both unstabilised and stabilised compressed earth bricks to adsorb/release water vapour as ambient humidity changes has been assessed by means of dynamic vapour sorption tests. Results from DVS tests are presented in Fig. 9 in terms of average mass change (i.e. the difference between current and initial mass divided by the initial mass) from two DVS tests performed on each material composition. Inspection of Fig. 9 confirms the excellent capability of the unstabilised material to buffer water vapour during the cyclic variation of relative humidity, which is due to the presence of the illite and montmorillonite fractions with a high specific surface and a strong hydrophilic behaviour $[51,55]$. This is also consistent with the weak liquid water durability of the unstabilised materials observed during both immersion and drip tests. Figure 9 also shows that both cement and biopolymer stabilisation reduced the moisture buffering capacity of the material. This is because both stabilisations occluded the pores where evaporation and condensation of water vapour naturally occur under the hygrothermal conditions imposed during DVS tests. Inspection of Fig. 9 also suggests that the hygroscopic behaviour of the samples stabilised with $8 \%$ of cement is similar to that of samples stabilised with $2 \%$ of guar gum, while a further increase of the biopolymer content induced a more significant reduction of the moisture buffering

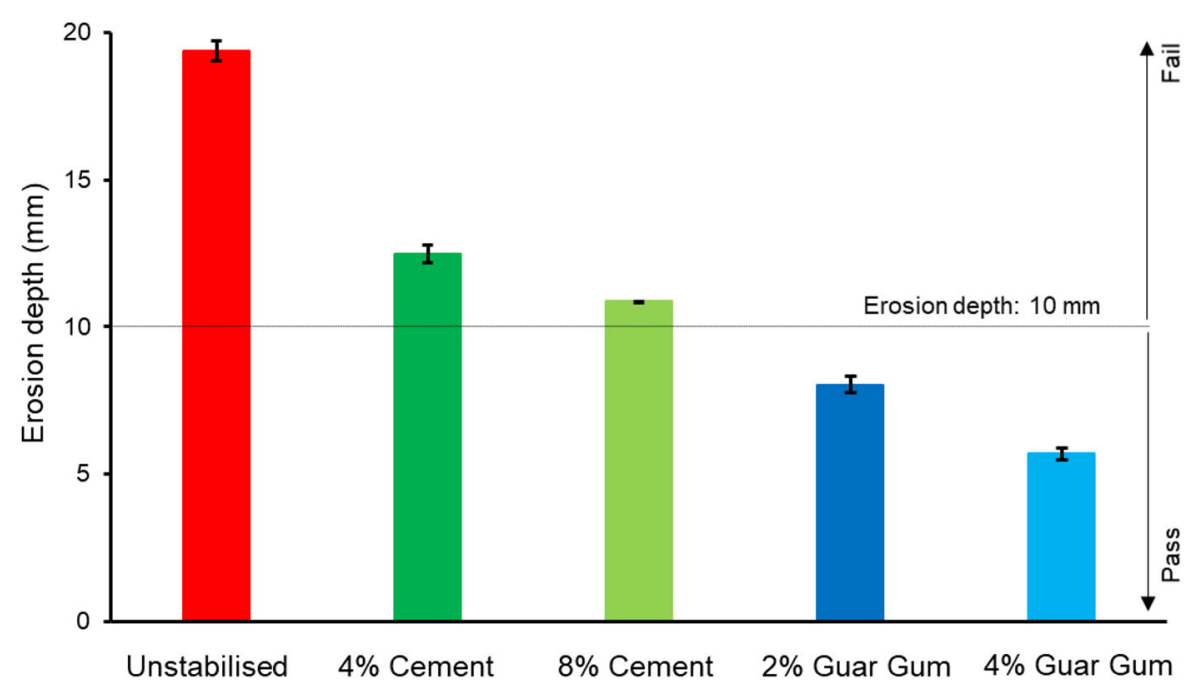

Fig. 8 Erosion depth after drip tests of unstabilised and stabilised compressed earth bricks 


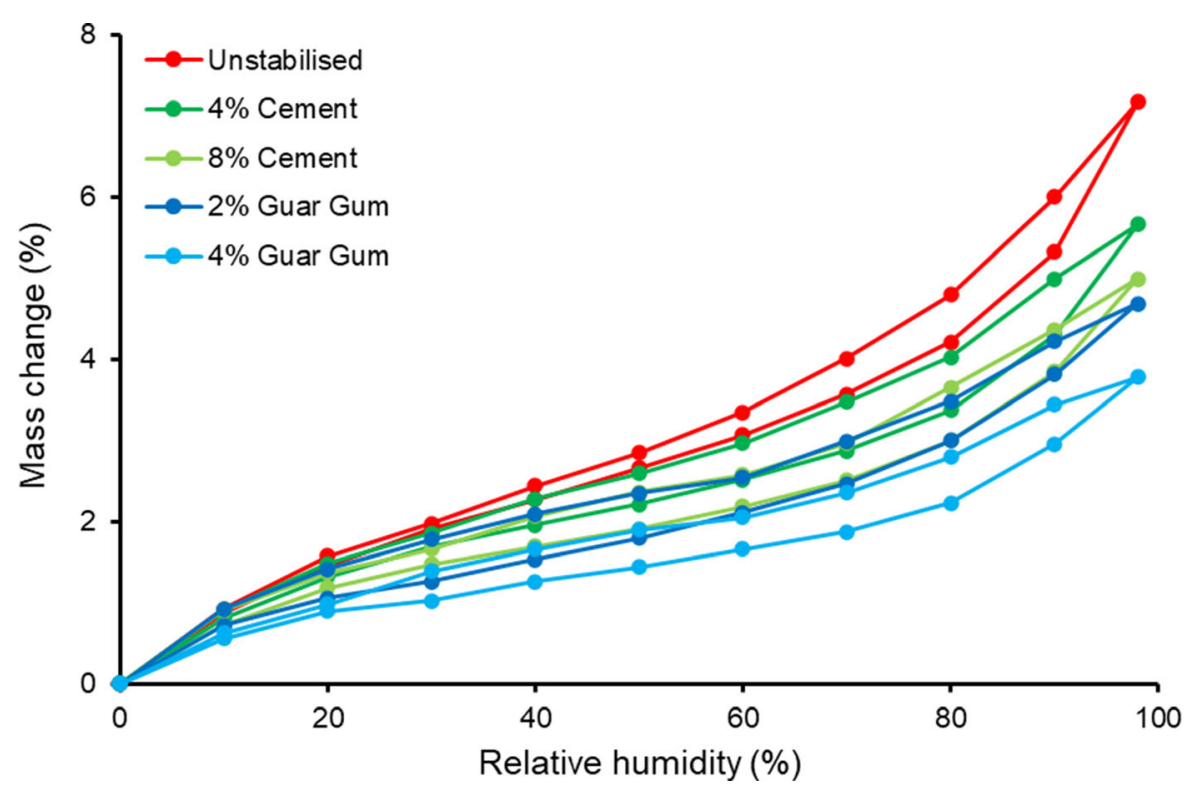

Fig. 9 Mass change during DVS tests of unstabilised and stabilised compressed earth bricks

capacity. Numerical values of the maximum standard deviation for each brick composition are also reported in Table 2. All brick compositions exhibited the maximum standard deviation at the highest level of relative humidity of $98 \%$ and this can be related either to slightly different adsorption capacity due to the heterogeneity of the material or to the chosen equalisation criterion adopted for the DVS tests. Moreover, the unstabilised earth bricks exhibited the lowest scatter of results followed by the cement- and guar gum-stabilised bricks.

Results from DVS tests are also plotted in Fig. 10 in terms of hysteresis (i.e. the difference in mass change between the desorption and sorption curves at a given value of relative humidity) for each brick composition. Inspection of Fig. 10 indicates that both cement and bio-polymer stabilisations induced a more significant

Table 2 Maximum standard deviation for all brick compositions measured during DVS tests

\begin{tabular}{ll}
\hline Sample & Maximum stadard deviation $(\%)$ \\
\hline Unstabilised & 0.046 \\
$4 \%$ Cement & 0.074 \\
$8 \%$ Cement & 0.133 \\
$2 \%$ Guar gum & 0.127 \\
$4 \%$ Guar gum & 0.306
\end{tabular}

hysteretic behaviour compared with the unstabilised material for a relative humidity up to $70 \%$, as also observed by Cagnon et al. [56]. For this range of ambient humidity, the limited hysteresis of the unstabilised material can be associated with its high breathing ability to exchange water vapour as relative humidity changes. For higher levels of relative humidity, the increase of hysteresis for the unstabilised samples can be instead related to the large intake of water vapour, which was not readily released at the reversal point between the sorption and the desorption curves. Interestingly, Fig. 10 also suggests that the biopolymer and cement stabilisation induced two distinct effects on the hygroscopic behaviour of the material. In particular, the biopolymer stabilisation tended to increase the hysteresis at a relative humidity up to $50 \%$ and this suggests that guar gum mostly affected the connectivity of the smaller pores involved in the condensation/evaporation of water vapour occurring at this range of relative humidity. This is also in agreement with results from the liquid water durability tests, which showed the good performance of the biopolymer stabilised bricks as a consequence of the occlusion of the smallest pores and hence the limitation of the swelling potential of the clay fraction of the material. Cement stabilised samples exhibited instead a more significant influence on the larger pores 


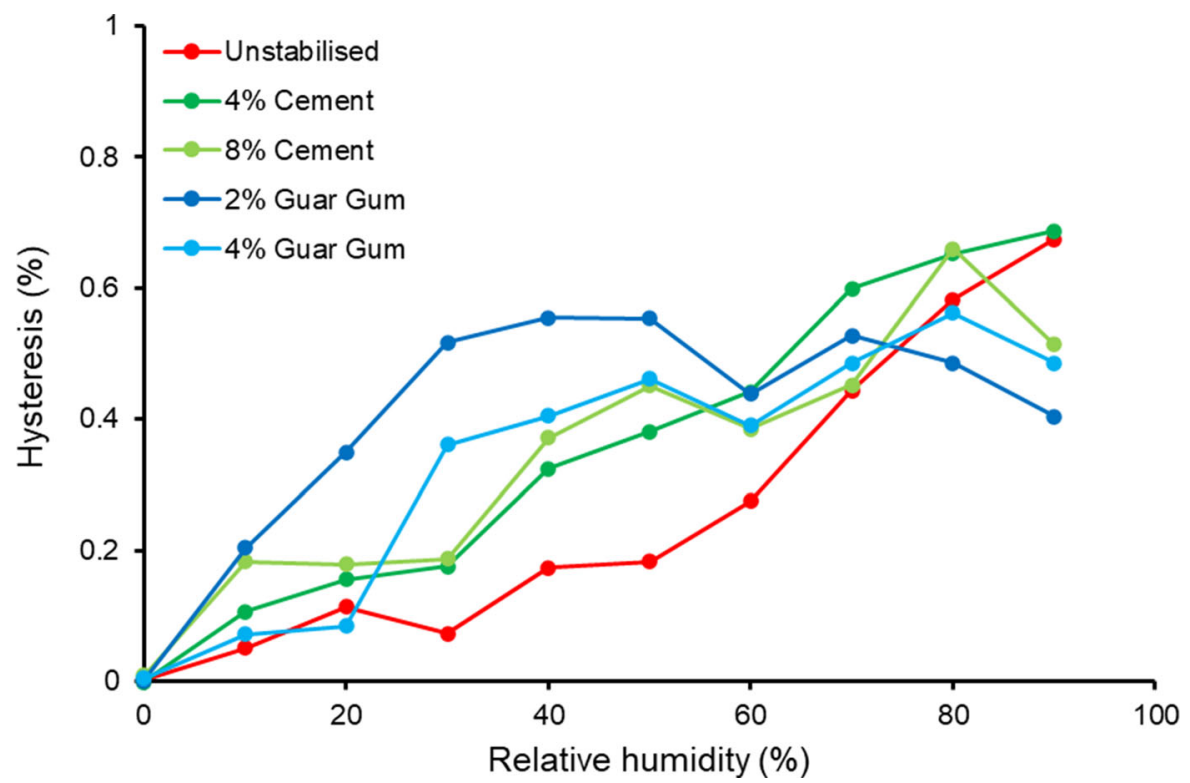

Fig. 10 Hysteresis of unstabilised and stabilised compressed earth bricks measured during DVS tests

which are involved in the condensation/evaporation of water vapour at the high levels of relative humidity.

In conclusion, compressed earth bricks stabilised with a low percentage of guar gum offered a good balance between mechanical behaviour, recyclability, liquid water durability and water vapour adsorption. Considering that the production of guar gum requires a relatively low level of embodied energy, it is predictable that this stabilisation method also provides better environmental performance compared with that of cement stabilisation. However, this statement would need to be supported by a quantitative study based, for instance, on life cycle assessments. This type of analysis is however considered outside the scope of the present work.

\section{Conclusions}

The present paper investigated the effect of recycling on the mechanical behaviour of unstabilised and stabilised compressed earth bricks. Earth stabilisation involved either addition of ordinary Portland cement or the bio-polymerisation of the base earth by means of guar gum. Both unstabilised and stabilised bricks were also subjected to immersion and drip tests to explore the influence of stabilisation on the water durability of the bricks. Another set of laboratory tests was finally performed to assess the capacity of unstabilised and stabilised compressed earth bricks in adsorbing/releasing water vapour as the surrounding relative humidity changes. The main outcomes of this research can be summarised as follows:

- Both cement and biopolymer stabilisation improved the mechanical properties of the compressed earth bricks in comparison with the unstabilised samples. This is associated with the bonding of soil particles generated by both stabilisation methods.

- Recycling only induced negligible changes in the mechanical performance of unstabilised compressed earth bricks and this is associated with capillary actions, which were only marginally affected by the recycling process.

- Biopolymer stabilised compressed earth bricks exhibited a slight improvement of mechanical properties after recycling. This is due to the improved bonding of the guar gum produced by the drying stage of the recycling process.

- Cement stabilised earth bricks exhibited a significant reduction of mechanical properties after recycling, with final stiffness and strength similar to those of the unstabilised materials. This is associated with the breakage of cement bonds between soil particles occurring during sample destruction and subsequent re-compaction. 
- The recycling process had opposite effect on cement- and guar gum-stabilised bricks. This suggests that stabilisation is not necessarily detrimental to the recycling of earth bricks and that bespoke investigation should be carried for each stabilisation method.

- Both stabilisation methods induced major improvements in the liquid water durability of compressed earth bricks as resulted from both immersion and drip tests, with the guar gum stabilisation outperforming the cement stabilisation as shown from both immersion and drip tests.

- Dynamic vapour sorption tests confirmed the excellent capacity of unstabilised earth bricks in exchanging moisture with the environment as relative humidity changes, while both cement and biopolymer stabilisations reduced the moisture buffering capacity

- Compressed earth bricks stabilised with a relatively low percentage of guar gum offered a good balance between mechanical behaviour, recyclability, liquid water durability and water vapour adsorption.

Finally, the present work has presented an unprecedented study on the recyclability of earth materials, which has the potential to trigger new research into the end-of-life of earth materials. Outcomes from this research will be particularly useful for environmental studies and life cycle assessments in a circular economy perspective.

\section{Funding None.}

\section{Compliance with ethical standards}

Conflict of interest The authors declare that they have no conflict of interest.

Open Access This article is licensed under a Creative Commons Attribution 4.0 International License, which permits use, sharing, adaptation, distribution and reproduction in any medium or format, as long as you give appropriate credit to the original author(s) and the source, provide a link to the Creative Commons licence, and indicate if changes were made. The images or other third party material in this article are included in the article's Creative Commons licence, unless indicated otherwise in a credit line to the material. If material is not included in the article's Creative Commons licence and your intended use is not permitted by statutory regulation or exceeds the permitted use, you will need to obtain permission directly from the copyright holder. To view a copy of this licence, visit http://creativecommons.org/licenses/by/4.0/.

\section{References}

1. Morel JC, Mesbah A, Oggero M, Walker P (2001) Building houses with local materials: means to drastically reduce the environmental impact of construction. Build Environ 36(10):1119-1126. https://doi.org/10.1016/S03601323(00)00054-8

2. Little B, Morton T (2001) Building with earth in Scotland: innovative design and sustainability. Scottish Executive Central Research Unit, Edinburgh. ISBN0-7559-0202-5

3. Allinson D, Hall M (2010) Hygrothermal analysis of a stabilised rammed earth test building in the UK. Energy Build 42(6):845-852. https://doi.org/10.1016/j.enbuild. 2009.12.005

4. Fabbri A, Al Haffar N, McGregor F (2019) Measurement of the relative air permeability of compacted earth in the hygroscopic regime of saturation. Comptes Rendus Mécanique 347(12):912-919. https://doi.org/10.1016/j.crme. 2019.11.017

5. Gallipoli D, Bruno AW, Perlot C, Mendes J (2017) A geotechnical perspective of raw earth building. Acta Geotech 12(3):463-478. https://doi.org/10.1007/s11440-0160521-1

6. Houben, H., \& Guillaud, H. (1989). Traité de construction en terre. Editions Parenthèses

7. McGregor F, Heath A, Fodde E, Shea A (2014) Conditions affecting the moisture buffering measurement performed on compressed earth blocks. Build Environ 75:11-18. https:// doi.org/10.1016/j.buildenv.2014.01.009

8. Pacheco-Torgal F, Jalali S (2012) Earth construction: lessons from the past for future eco-efficient construction. Constr Build Mater 29:512-519

9. Soudani L, Fabbri A, Morel JC, Woloszyn M, Chabriac PA, Wong H, Grillet AC (2016) Assessment of the validity of some common assumptions in hygrothermal modelling of earth based materials. Energy Build 116:498-511

10. Soudani L, Woloszyn M, Fabbri A, Morel JC, Grillet AC (2017) Energy evaluation of rammed earth walls using long term in-situ measurements. Sol Energy 141:70-80

11. Bossink BAG, Brouwers HJH (1996) Construction waste: quantification and source evaluation. J Construction Eng Manag 122(1):55-60

12. Dao K, Ouedraogo M, Millogo Y, Aubert JE, Gomina M (2018) Thermal, hydric and mechanical behaviours of adobes stabilized with cement. Constr Build Mater 158:84-96

13. Gomes MI, Gonçalves TD, Faria P (2016) Hydric behavior of earth materials and the effects of their stabilization with cement or lime: study on repair mortars for historical rammed earth structures. J Mater Civ Eng 28(7):04016041

14. Jayasinghe C, Kamaladasa N (2007) Compressive strength characteristics of cement stabilized rammed earth walls. Constr Build Mater 21(11):1971-1976

15. Kariyawasam KKGKD, Jayasinghe C (2016) Cement stabilized rammed earth as a sustainable construction material. Constr Build Mater 105:519-527

16. Venkatarama Reddy BV, Suresh V, Nanjunda Rao KS (2016) Characteristic compressive strength of cement-stabilized rammed earth. J Mater Civil Eng 29(2):04016203 
17. Walker P, Stace T (1997) Properties of some cement stabilised compressed earth blocks and mortars. Mater Struct 30(9):545-551

18. Muguda, S., Hughes, P. N., Augarde, C. E., Perlot, C., Gallipoli, D., \& Bruno, A. W. (2019). Geotechnical characterisation of recycled biopolymer-stabilised earthen materials. In proceedings of the XVII European conference on soil mechanics and geotechnical engineering ECSMGE, Reykjavik, Iceland.

19. Chudzikowski RJ (1971) Guar gum and its applications. J Soc Cosmet Chem 22(1):43

20. Mudgil D, Barak S, Khatkar BS (2014) Guar gum: processing, properties and food applications-a review. J Food Sci Technol 51(3):409-418

21. Muguda S, Lucas G, Hughes PN, Augarde CE, Perlot C, Bruno AW, Gallipoli D (2020) Durability and hygroscopic behaviour of biopolymer stabilised earthen construction materials. Constr Build Mater 259:119725

22. Ayeldeen MK, Negm AM, El Sawwaf MA (2016) Evaluating the physical characteristics of biopolymer/soil mixtures. Arab J Geosci 9(5):371. https://doi.org/10.1007/ s12517-016-2366-1

23. Bouazza A, Gates WP, Ranjith PG (2009) Hydraulic conductivity of biopolymer-treated silty sand. Géotechnique 59(1):71-72

24. Qureshi MU, Chang I, Al-Sadarani K (2017) Strength and durability characteristics of biopolymer-treated desert sand. Geomech Eng 12(5):785-801. https://doi.org/10.12989/ gae.2017.12.5.785

25. MOPT (1992). Bases Para el Diseño y Construcción con Tapial. Madrid, Spain: Centro de Publicaciones, Secretaría General Técnica, Ministerio de Obras Públicas y Transportes.

26. CRATerre-EAG (1998). CDI, Compressed earth blocks: Standards-Technology series No.11. Brussels: CDI.

27. AFNOR (2001). XP P13-901; Compressed earth blocks for walls and partitions: definitions-Specifications-Test methods-Delivery acceptance conditions

28. AFNOR (1995). XP P 94-041. Soils: investigation and testing-Granulometric description-Wet sieving method

29. AFNOR (1992). NF P 94-057. Soils: investigation and testing-Granulometric analysis-Hydrometer method

30. Jaquin, P. A., Augarde, C. E., \& Legrand, L. (2008). Unsaturated characteristics of rammed earth. In first European conference on unsaturated soils, Durham, England (pp. 417-422).

31. Beckett, C. T. S., \& Augarde, C. E. (2012). The effect of humidity and temperature on the compressive strength of rammed earth. In proceedings of 2nd European conference on unsaturated soils (pp. 287-292)

32. AFNOR (1993). NF P 94-051; Soils: Investigation and testing-Determination of Atterberg's limits-Liquid limit test using Casagrande apparatus - Plastic limit test on rolled thread

33. ASTM D2487-11 (2011). Standard Practice for Classification of Soils for Engineering Purposes. Unified Soil Classification System, USCS

34. Houben H, Guillaud H (1994) Earth construction: a comprehensive guide. Intermediate Technology Publications, England
35. Skempton, A. W. (1953). The colloidal activity of clays. Selected Papers on Soil Mechanics, 106-118.

36. Bruno AW, Perlot C, Mendes J, Gallipoli D (2018) A microstructural insight into the hygro-mechanical behaviour of a stabilised hypercompacted earth. Mater Struct 51(1):32

37. Dierks, K., \& Ziegert, C. (2002). Neue Untersuchungen zum Materialverhaltenvon Stampflehm. Steingass, P.: Moderner Lehmbau 2002

38. Chang I, Prasidhi AK, Im J, Cho GC (2015) Soil strengthening using thermo-gelation biopolymers. Constr Build Mater 77:430-438

39. Muguda S, Booth SJ, Hughes PN, Augarde CE, Perlot C, Bruno AW, Gallipoli D (2017) Mechanical properties of biopolymer-stabilised soil-based construction materials. Géotech Lett 7(4):309-314

40. Bui QB, Morel JC, Hans S, Walker P (2014) Effect of moisture content on the mechanical characteristics of rammed earth. Constr Build Mater 54:163-169

41. Bruno, A.W. (2016). Hygro-mechanical characterisation of hypercompacted earth for building construction. $\mathrm{PhD}$ Thesis

42. Bruno, A. W., Gallipoli, D., Perlot, C., \& Mendes, J. (2016). Effect of very high compaction pressures on the physical and mechanical properties of earthen materials. In E3S web of conferences (Vol. 9, p. 14004). EDP Sciences

43. Wei Y, Guo W, Liang S (2016) Microprestress-solidification theory-based tensile creep modeling of early-age concrete: considering temperature and relative humidity effects. Constr Build Mater 127:618-626

44. Aubert JE, Fabbri A, Morel JC, Maillard P (2013) An earth block with a compressive strength higher than $45 \mathrm{MPa}$ ! Constr Build Mater 47:366-369

45. Morel JC, Pkla A, Walker P (2007) Compressive strength testing of compressed earth blocks. Constr Build Mater 21(2):303-309

46. Shen J, Xu Q (2019) Effect of moisture content and porosity on compressive strength of concrete during drying at $105 \mathrm{C}$. Constr Build Mater 195:19-27

47. Bradley TD, Ball A, Harding SE, Mitchell JR (1989) Thermal degradation of guar gum. Carbohyd Polym 10(3):205-214

48. Srivastava A, Mishra V, Singh P, Srivastava A, Kumar R (2012) Comparative study of thermal degradation behavior of graft copolymers of polysaccharides and vinyl monomers. J Therm Anal Calorim 107(1):211-223

49. Yagoub NA, Nur AO (2013) The Influence of thermal treatment on physical properties of guar gum. Int J Innov Pharm Sci 2:26-31

50. AENOR (2008). UNE 41410; Compressed earth blocks for walls: definitions, specifications and testing methods

51. Bruno AW, Gallipoli D, Perlot C, Mendes J (2017) Effect of stabilisation on mechanical properties, moisture buffering and water durability of hypercompacted earth. Constr Build Mater 149:733-740

52. Tarantino A, De Col E (2008) Compaction behaviour of clay. Géotechnique 58(3):199-213

53. Gallipoli D, Bruno AW, Perlot C, Salmon N (2014) Raw earth construction: is there a role for unsaturated soil mechanics. Research and Applications, Unsaturated Soils, pp 55-62 
54. Jaquin PA, Augarde CE, Gallipoli D, Toll DG (2009) The strength of unstabilised rammed earth materials. Géotechnique 59(5):487-490

55. McGregor F, Heath A, Maskell D, Fabbri A, Morel JC (2016) A review on the buffering capacity of earth building materials. Proc Inst Civil Eng-Constr Mater 169(5):241-251
56. Cagnon H, Aubert JE, Coutand M, Magniont C (2014) Hygrothermal properties of earth bricks. Energy Build 80:208-217

Publisher's Note Springer Nature remains neutral with regard to jurisdictional claims in published maps and institutional affiliations. 